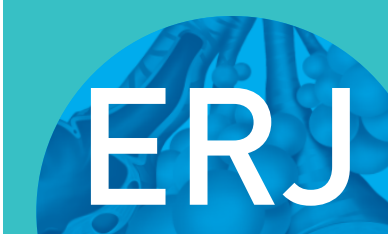

open research

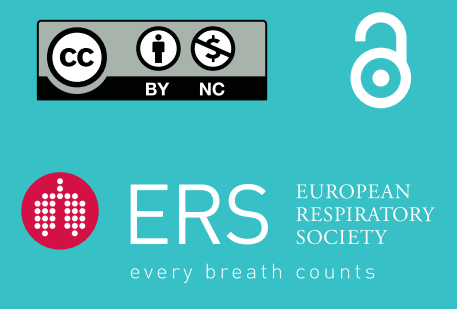

\section{Corticosteroid-resistant inflammatory signalling in Pseudomonas-infected bronchial cells}

\author{
Mirai Mizutani ${ }^{1}$, Julie Bérubé ${ }^{1}$, Heather G. Ahlgren ${ }^{2}$, Joanie Bernier ${ }^{3}$, \\ Elias Matouk ${ }^{3}$, Dao Nguyen ${ }^{1,2,4}$ and Simon Rousseau ${ }^{1,2,4}$
}

Affiliations: ${ }^{1}$ Meakins-Christie Laboratories, Research Institute of the McGill University Health Centre, Montreal, QC, Canada. ${ }^{2}$ Dept of Medicine, McGill University, Montreal, QC, Canada. ${ }^{3}$ Adult Cystic Fibrosis Clinic, Montreal Chest Institute, McGill University Health Centre, Montreal, QC, Canada. ${ }^{4}$ These authors contributed equally to this work.

Correspondence: Simon Rousseau, The Meakins-Christie Laboratories at the RI-MUHC, 1001 Boulevard Décarie, Montreal, QC H4A 3J1, Canada. E-mail: simon.rousseaudmcgill.ca

ABSTRACT Decreasing the inflammatory response that leads to tissue damage during cystic fibrosis (CF) lung disease has been a long-standing goal of CF therapy. While corticosteroids are widely used antiinflammatory drugs, their efficacy in CF lung disease remains debated. The complex interaction between the colonising bacteria and the host environment may impact corticosteroid responsiveness.

In this study, sputum samples from adult CF patients were collected at baseline and during pulmonary exacerbation episodes. Lung function measurements and sputum microbiological analyses were performed. In parallel, the inflammatory response and corticosteroid sensitivity of airway epithelial cells to Pseudomonas-derived exoproducts was investigated.

We report that adult CF patients colonised with mucoid Pseudomonas aeruginosa have higher levels of baseline inflammation, more frequent exacerbations and worse lung function compared with patients colonised with nonmucoid $P$. aeruginosa. Moreover, mucoid $P$. aeruginosa activates NF- $\mathrm{B}$ via Toll-like receptor (TLR) 2, which acts in an additive manner to TLR5 to drive inflammation in airway epithelial cells. Furthermore, TLR2-mediated intracellular signalling is more resistant to the anti-inflammatory effects of corticosteroid when compared with other TLR signalling pathways.

Overall, these results suggest that airway inflammation triggered by mucoid $P$. aeruginosa is less responsive to the anti-inflammatory action of corticosteroids. Whether this translates into a diminished response of CF patients to corticosteroid therapy should be examined in future clinical studies.

$@$ ERSpublications

TLR2 activation by mucoid Pseudomonas increases corticosteroid-resistant inflammation in airway epithelial cells http://ow.ly/lR3d30bsRrr

Cite this article as: Mizutani M, Bérubé J, Ahlgren HG, et al. Corticosteroid-resistant inflammatory signalling in Pseudomonas-infected bronchial cells. ERJ Open Res 2017; 3: 00144-2016 [https:// doi.org/10.1183/23120541.00144-2016].

Received: Nov 302016 | Accepted after revision: April 172017

Support statement: We acknowledge the financial support of the Natural Sciences and Engineering Research Council of Canada, the Canadian Institute of Health Research (MOP\#123496), Cystic Fibrosis Canada (two grants, one to S. Rousseau and one to D. Nguyen) and Burroughs Wellcome Fund (D. Nguyen). The Meakins-Christie Laboratories, Research Institute of the McGill University Health Centre, are supported by a Centre grant from Les Fonds de Recherche Québec-Santé (FRQ-S). D. Nguyen and S. Rousseau are supported by FRQ-S salary awards. Funding information for this article has been deposited with the Crossref Funder Registry.

Conflict of interest: Disclosures can be found alongside this article at openres.ersjournals.com

Copyright $\odot$ ERS 2017. This article is open access and distributed under the terms of the Creative Commons Attribution Non-Commercial Licence 4.0. 


\section{Introduction}

Pulmonary exacerbations are important clinical events during cystic fibrosis (CF) lung disease as they can result in a net decline of lung function from the pre-exacerbation state [1]. Although antibiotic therapy resolves the clinical symptoms associated with most pulmonary exacerbations, it fails to prevent the decline in lung function that occurs over the course of repeated pulmonary exacerbations. Inflammation driven by bacterial infection is a major contributor to lung tissue destruction in CF [2], which may account for the loss of lung function following pulmonary exacerbations. Calprotectin is an abundant neutrophilic protein complex that is a marker of inflammation in $\mathrm{CF}[3]$.

Pseudomonas aeruginosa, a Gram-negative bacterium that chronically infects the lungs of CF patients [4], can trigger inflammation via activation of airway epithelium sensors, such as Toll-like receptor (TLR) 5 binding to flagellin [5-8]. Importantly, $P$. aeruginosa strains that infect CF patients show significant phenotypic diversity. One major bacterial adaptation is the acquisition of a mucoid phenotype, with $70 \%$ of all isolated strains from CF patients exhibiting this phenotype at one point or another [9]. Infection with mucoid $P$. aeruginosa is associated with poor survival in CF children [10] and greater decline in lung function in young CF adults [11]. Interestingly, the switch of $P$. aeruginosa to a mucoid phenotype leads to increased lipopeptide synthesis that is accompanied by activation of TLR2 in human airway epithelial cells $[12,13]$. This raises the possibility that mucoid $P$. aeruginosa is not only a marker of more severe lung disease but may in fact induce greater lung inflammation, thus directly contributing to the pathogenesis of CF lung disease.

Therefore, anti-inflammatory therapy combined with antibiotics may mitigate the accelerated lung function associated with pulmonary exacerbation events. The use of corticosteroids as an anti-inflammatory therapy in the treatment of CF remains unclear. Chronic systemic glucocorticoid therapy in CF can improve lung function [14,15], but is associated with significant adverse effects [16]. Cochrane reviews of both oral and inhaled corticosteroids in CF also fail to provide clear guidelines for the use of corticosteroids in CF [17, 18]. A key to the use of corticosteroids in CF may be the identification of patients that benefit most from their use. We hypothesise that corticosteroids have differential anti-inflammatory effects based on the inflammatory signalling pathways that are activated by $P$. aeruginosa.

\section{Material and methods \\ Study cohort}

Adult patients followed at the Montreal Chest Institute Adult CF Clinic (Montreal, QC, Canada) were enrolled in a prospective observational cohort study, as previously described [19]. 53\% of patients were female and the mean $\pm \mathrm{SD}$ age was $33 \pm 13.6$ years. The mean $\pm \mathrm{SD}$ forced expiratory volume in $1 \mathrm{~s}(\mathrm{FEV} 1) \%$ pred was $62.6 \pm 28.27 \%$, representing a moderate level of disease severity. The mean \pm SD body mass index was $21.9 \pm 4.16 \mathrm{~kg} \cdot \mathrm{m}^{-2}$, representing adequate nutritional status. Patients were evaluated during a stable clinical state when sputum, blood and lung function were measured. Clinical stability was defined as a period of at least 28 days without intravenous or oral antibiotics (excluding chronic antibiotic treatment). The European Consensus Group's view was used to define a pulmonary exacerbation as the need for additional antibiotic treatment as indicated by a recent change in at least two of the following criteria: a change in sputum volume or colour; increased coughing; increased dyspnoea; increased malaise, fatigue or lethargy; anorexia or weight loss; and a decrease in pulmonary function by $\geqslant 10 \%$ or radiographic changes [20-22]. We also extracted from the patients' medical records the number of i.v.-treated pulmonary exacerbations 1 year prior to baseline. Lung spirometry (FEV1) was performed according to the American Thoracic Society standards [23]. Spontaneously expectorated sputum samples were analysed by the McGill University Health Centre clinical microbiology laboratory (Montreal, QC, Canada) per standard protocols for CF samples. Mucoid and nonmucoid P. aeruginosa strains were identified by colony morphology on McConkey agar plates. Calprotectin levels were measured from plasma samples using an ELISA kit from Hycult Biotech (Uden, The Netherlands). All study participants provided written informed consent. The study was approved by the Research Ethics Board of the McGill University Health Centre.

\section{Materials}

All chemicals were from Fisher Scientific (Fair Lawn, NJ, USA). FSL-1, Pam3CSK4 and Salmonella typhimurium flagellin were from Invivogen (San Diego, CA, USA). Dexamethasone was from Cayman Chemical (Ann Arbor, MI, USA). Passive lysis $5 \times$ buffer was from Promega (Madison, WI, USA).

\section{Epithelial cell culture}

BEAS-2B airway epithelial cells were cultured as previously described [24]. HEK293 NF- $\kappa$ B and HEK293 GRE (glucocorticoid response element) cells were cultured in DMEM with 5\% fetal bovine serum and $200 \mu \mathrm{g} \cdot \mathrm{mL}^{-1}$ hygromycin. 
Cell lysis, RNA extraction and quantitative real-time PCR

All the techniques were performed as previously described [24]. Quantitative real-time PCR primer sequences for mitogen-activated protein kinase (MAPK) phosphatase-1 (MKP-1) are 5'-CTG CCT TGA TCA ACG TCT CA-3' and 5'-ACC CTT CCT CCA GCA TTC TT-3'.

\section{$N F-\kappa B$ and GRE luciferase reporter cell lines}

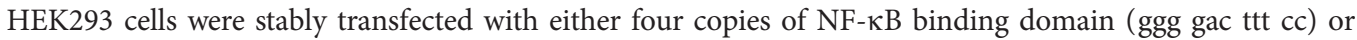
four copies of GRE (ggt aca ttt tgt tct), cloned in tandem in pGL4.28 vector (Promega) that encodes for luciferase. Transfected cells were selected for their resistance to $200 \mu \mathrm{g} \cdot \mathrm{mL}^{-1}$ hygromycin. Cells were stimulated for $3 \mathrm{~h}$, then lysed using passive lysis $1 \times$ buffer. The luciferase activity was measured using a Tecan plate reader (Tecan, Männedorf, Switzerland), in luciferase assay reagent (20 mM Tricine, $1.07 \mathrm{mM}$ $\left(\mathrm{MgCO}_{3}\right)_{4} \mathrm{Mg}(\mathrm{OH})_{2}, 2.67 \mathrm{mM} \mathrm{MgSO}_{4}, 0.1 \mathrm{mM}$ EDTA, $33.3 \mathrm{mM}$ dithiothreitol, $270 \mu \mathrm{M}$ coenzyme A, $4.7 \mathrm{mM}$ luciferin, $5.3 \mathrm{mM}$ ATP).

\section{Statistical analysis}

The t-test was used for comparison of means of all disease variables between the low and high calprotectin groups. A Poisson regression model was used to estimate the interactions between baseline continuous calprotectin values, FEV1 \% pred and frequency of pulmonary exacerbations. Significance was set at $\mathrm{p}<0.05$. Data were analysed using SAS version 9.4 (SAS Institute, Cary, NC, USA). ANOVA followed by a multiple comparison test (Bonferroni) was used to test differences in mean between groups using Prism 6 (GraphPad, La Jolla, CA, USA) for figures 2 and 3. $\mathrm{p}<0.05$ was considered significant.

\section{Results}

Adult CF patients with higher plasma calprotectin have worse lung function, more frequent pulmonary exacerbations and high prevalence of mucoid $\mathrm{P}_{\text {. aeruginosa }}$

Plasma calprotectin levels were measured in a cohort of 49 adult CF patients during stable clinical state as an indicator of neutrophilic inflammation in CF. The mean \pm SD calprotectin level was $146 \pm 157.1 \mathrm{ng} \cdot \mathrm{L}^{-1}$ (range 3.6-511 ng. $\mathrm{L}^{-1}$ ), with a median (interquartile range) of $69.3(26.1-243) \mathrm{ng} \cdot \mathrm{L}^{-1}$. Calprotectin levels were negatively correlated with $\mathrm{FEV}_{1} \%$ pred $(\mathrm{r}=-0.41, \mathrm{p}=0.002)$ (figure 1a). Importantly, CF patients with calprotectin levels $>150 \mathrm{ng} \cdot \mathrm{mL}^{-1}$ experienced more pulmonary exacerbation events in the year preceding as well as following the initial baseline visit (table 1).

Moreover, mucoid P. aeruginosa was more frequently isolated in sputum samples from the high calprotectin groups ( $82 \%$ versus $32 \%$ ) (figure $1 \mathrm{~b}$ and c). Accordingly, the presence of mucoid P. aeruginosa was associated with higher levels of calprotectin $\left(184.5 \pm 160 \mathrm{ng} \cdot \mathrm{mL}^{-1} ; \mathrm{n}=24\right)$ versus other infections $\left(77.6 \pm 99.9 \mathrm{ng} \cdot \mathrm{mL}^{-1} ; \mathrm{n}=21\right)(\mathrm{p}=0.0096, \mathrm{t}$-test $)$.
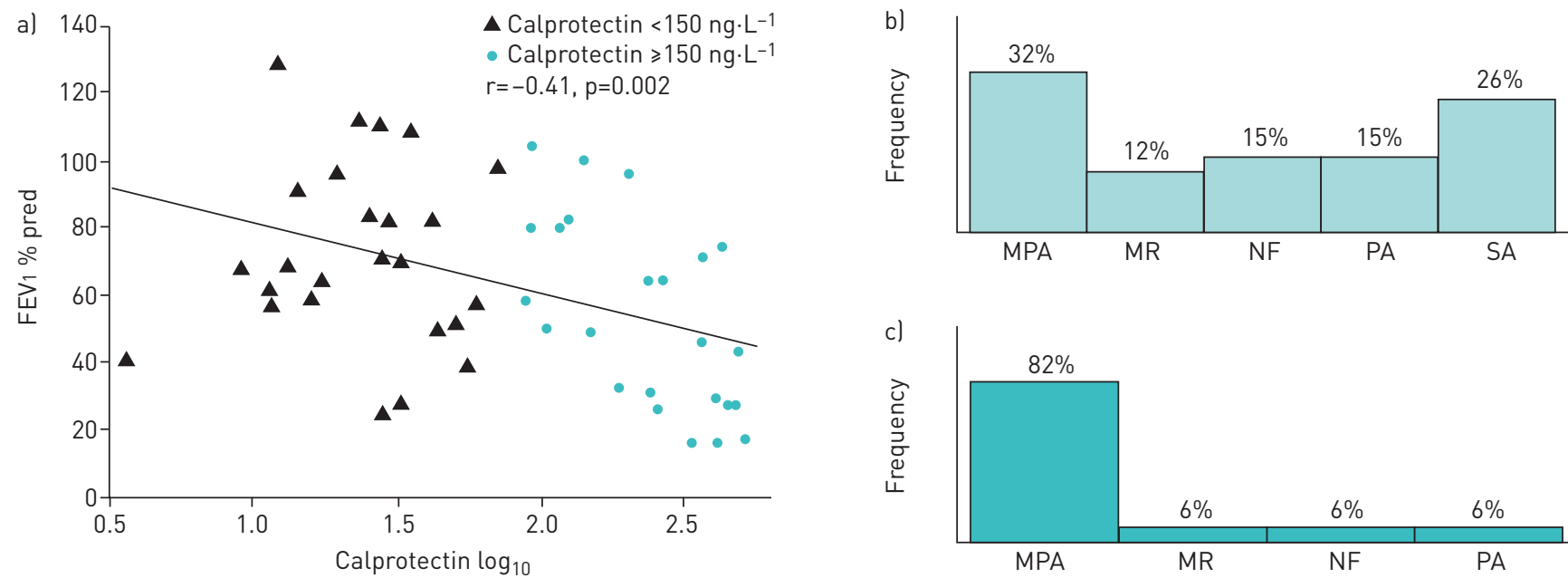

FIGURE 1 Higher circulating calprotectin levels are associated with lower lung function and the presence of mucoid Pseudomonas aeruginosa. a) Calprotectin circulating levels were measured by ELISA in the plasma collected from 49 adult cystic fibrosis (CF) patients of the Montreal Chest Institute Adult CF Clinic during a stable clinic visit (i.e. the patient had not experienced a pulmonary exacerbation within the previous 2 months). During the visit spirometry measurements were performed to determine forced expiratory volume in $1 \mathrm{~s}$ (FEV1) \% pred. A Poisson regression model was used to estimate the interactions between baseline continuous calprotectin values and FEV $1 \%$ pred. b, c) Frequency distribution of sputum microbiology status in b) low (<150 $\mathrm{ng} \cdot \mathrm{mL}^{-1}$ ) versus c) high ( $\geqslant 150 \mathrm{ng} \cdot \mathrm{mL}^{-1}$ ) calprotectin groups. MPA: mucoid $P$. aeruginosa; $\mathrm{MR}$ : multidrug-resistant $P$. aeruginosa; NF: normal flora; PA: nonmucoid $P$. aeruginosa; SA: Staphylococcus aureus. 


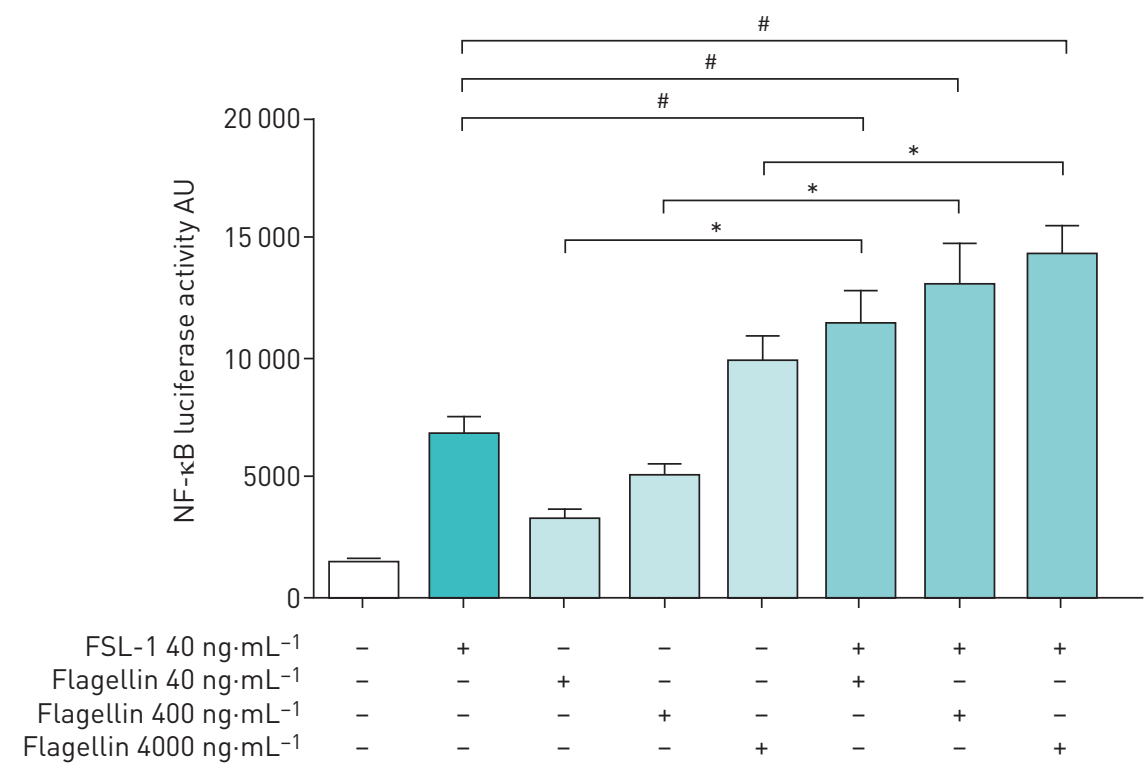

FIGURE 2 Additive activation of NF-kB upon dimerisation of Toll-like receptor (TLR) 5 and TLR2. BEAS-2B epithelial cells stably transfected with an $\mathrm{NF}-\kappa \mathrm{B}$ luciferase reporter were treated with increasing concentrations of flagellin $\left(40,400\right.$ and $\left.4000 \mathrm{ng} \cdot \mathrm{mL}^{-1}\right)$ in the absence or presence of $40 \mathrm{ng} \cdot \mathrm{mL}^{-1} \mathrm{FSL}-1$ for $3 \mathrm{~h}$. Cells were lysed using reporter lysis buffer and luciferase activity was measured using a Tecan plate. AU: arbitrary unit. *: $p<0.05$ flagellin compared with flagellin+FSL-1; \#: $p<0.05$ FSL-1 compared with flagellin+FSL-1.

\section{Additive activation of MyD88-dependent signalling upon dimerisation of TLR5 and TLR2}

As mucoid $P$. aeruginosa is associated with more frequent pulmonary exacerbations and greater inflammation, this led us to investigate the molecular interactions between mucoid $P$. aeruginos $a$ and airway epithelial cells. Mucoidy is associated with increased lipopeptide synthesis and engagement of TLR2 (see Introduction).

We asked whether activating TLR2 in addition to TLR5 influences the magnitude of the inflammatory response. The bronchial epithelial cell line BEAS-2B expressing a stable NF- $\kappa$ B luciferase reporter was exposed to increasing flagellin concentrations in the absence or presence of a TLR2/TLR6 agonist, FSL-1. At every experimental point measured, NF- $\kappa \mathrm{B}$ luciferase activity was higher when the two agonists were combined than when either was used alone (figure 2). These results suggest a potential for greater inflammation when agonists for TLR5 and TLR2 are present.

\section{TLR2-induced inflammatory signalling is more resistant to dexamethasone than TLR5-driven signalling}

Corticosteroids have potent anti-inflammatory activity and are occasionally used in the treatment of CF pulmonary exacerbations. This led us to examine their impact on TLR-dependent inflammatory signalling. In the BEAS-2B NF- $\kappa \mathrm{B}$ reporter cells, dexamethasone significantly inhibited flagellin (TLR5)- or polyinosinic-polycytidylic acid (TLR3)-induced NF- $\mathrm{\kappa B}$ activation (up to $56 \%$ and $72 \%$, respectively). In contrast, dexamethasone showed minimal impact on Pam3CSK4 (TLR1/TLR2)- or FSL-1 (TLR2/TLR6)dependent NF- $\kappa \mathrm{B}$ activation $(<20 \%)$, even at the highest dose of $1000 \mathrm{nM}$ (figure $3 \mathrm{a}$ ). Similar results were obtained when the effect of dexamethasone was tested on p38 $\alpha$ MAPK phosphorylation (figure $3 b$ ). Neither flagellin or Pam3CSK4 had any impact on induction of a GRE linked to luciferase or the endogenous expression of a gene whose expression is induced by corticosteroid, the protein phosphatase dual specificity phosphatase 1 (DUSP1) (figure $3 c$ and $d$ ). This rules out that these ligands interfered with the dexamethasone induction of GRE-regulated genes.

These results highlight the differential anti-inflammatory effects of corticosteroids on TLR signalling in airway epithelial cells. They suggest that TLR2-dependent inflammation, which occurs predominantly in response to mucoid $P$. aeruginosa, may be corticosteroid resistant.

\section{Discussion}

In this study, we observed in a prospective cohort of adult CF patients that those with higher baseline levels of calprotectin, a marker of inflammation, had worse lung function, more frequent pulmonary 


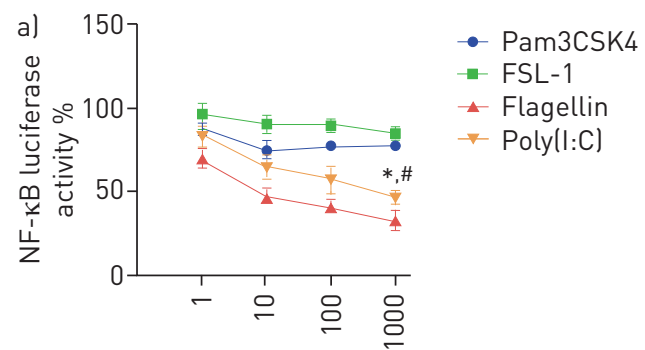

Dexamethasone $\mathrm{nM}$
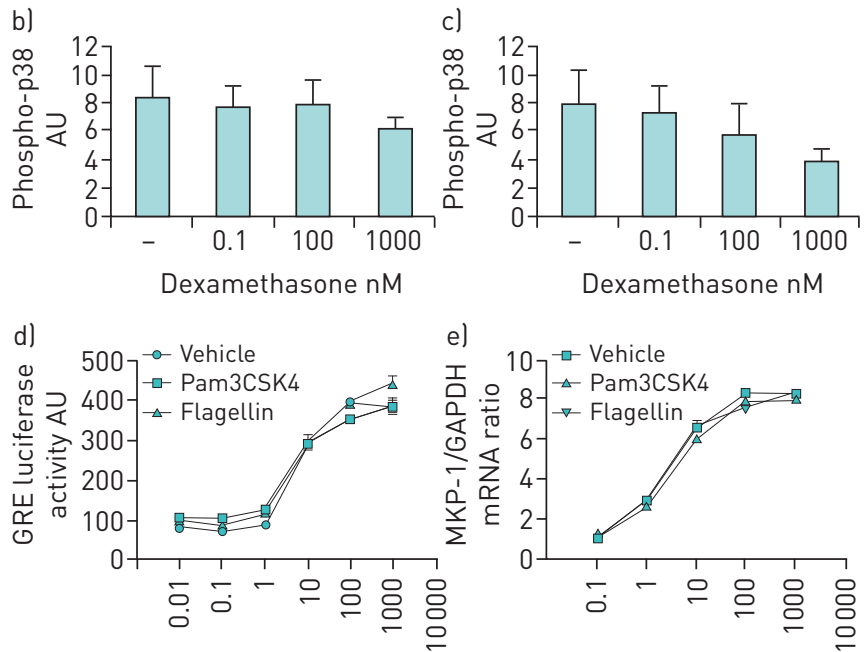

Dexamethasone $\mathrm{nM}$

Dexamethasone $\mathrm{nM}$

FIGURE 3 Toll-like receptor (TLR) 2-induced inflammatory signalling is more resistant to dexamethasone than TLR5-driven signalling. a) BEAS-2B NF- $\mathrm{BB}$ luciferase reporter cells were pre-treated for $1 \mathrm{~h}$ with increasing doses of dexamethasone $(0.1-1000 \mathrm{nM})$, then treated for $3 \mathrm{~h}$ with $1 \mu \mathrm{g} \cdot \mathrm{mL}^{-1}$ Pam3CSK4, $100 \mathrm{ng} \cdot \mathrm{mL}^{-1}$ flagellin, $40 \mathrm{ng} \cdot \mathrm{mL}^{-1} \mathrm{FSL}-1$ or $1 \mu \mathrm{g} \cdot \mathrm{mL}^{-1}$ polyinosinic-polycytidylic acid (poly(I:C)) and luciferase activity was measured. b, c) BEAS-2B cells were pre-treated for $1 \mathrm{~h}$ with increasing doses of dexamethasone (0.1-1000 nM), then treated for 30 min with either b) $1 \mu \mathrm{g} \cdot \mathrm{mL}^{-1}$ Pam3CSK4 or c) $100 \mathrm{ng} \cdot \mathrm{mL}^{-1} \mathrm{flagellin}$. Following stimulation, cells were lysed and $20 \mu \mathrm{g}$ of Triton-soluble material was subjected to SDS-PAGE. After transfer to nitrocellulose, the membranes were probed with antibodies recognising only the phosphorylated forms of p38 mitogen-activated protein kinase (MAPK) or antibodies that recognise all forms of p38 MAPK. Quantitative analysis of the signals from each antibody was performed using a LI-COR infrared Odyssey imaging system (LI-COR, Lincoln, NE, USA). AU: arbitrary unit. d, e) BEAS-2B glucocorticoid response element (GRE) luciferase reporter cells were treated for $1 \mathrm{~h}$ with increasing doses of dexamethasone (0.1-1000 nM). Cells were lysed and d) luciferase activity was measured as in figure 2 or el mRNA levels of MAPK phosphatase-1 (MKP-1) were quantified by quantitative real-time PCR. GAPDH: glyceraldehyde 3-phosphate dehydrogenase.

exacerbations and higher prevalence of mucoid $P$. aeruginosa. In parallel, using airway epithelial cells, we report that mucoid $P$. aeruginosa activates NF- $\kappa$ B via TLR2, which can act in an additive manner to TLR5 to drive inflammation. Moreover, TLR2-mediated intracellular signalling is more resistant to the anti-inflammatory effects of corticosteroids when compared with other TLR signalling pathways.

TABLE 1 Pulmonary exacerbation frequency in adult cystic fibrosis patients with high or low plasma levels of calprotectin

\begin{tabular}{|c|c|c|c|}
\hline & Calprotectin $<150 \mathrm{ng} \cdot \mathrm{L}^{-1}$ & Calprotectin $\geqslant 150 \mathrm{ng} \cdot \mathrm{L}^{-1}$ & p-value \\
\hline Subjects & 33 & 16 & \\
\hline \multicolumn{4}{|c|}{ Pulmonary exacerbations } \\
\hline 1-year prior & $0.45 \pm 0.97$ & $2.0 \pm 2.3$ & 0.019 \\
\hline 1-year post & $0.42 \pm 0.93$ & $2.5 \pm 2.47$ & 0.0048 \\
\hline
\end{tabular}


The clinical findings in CF patients reported here are consistent with past studies showing that mucoid $P$. aeruginosa colonisation of CF airways is associated with worse lung disease $[10,11]$. While such clinical studies only point towards an association, in vitro experimental systems can suggest mechanisms by which mucoid $P$. aeruginosa induces greater lung inflammation. Mucoid $P$. aeruginosa overexpress lipopeptides compared with their isogenic nonmucoid parental strain [12] and strongly activate TLR2 [12, 13]. In this study, it was found that concomitant activation of TLR5 and TLR2 is additive over a 1000-fold range of flagellin concentrations. This dual activation of the $\mathrm{NF}-\kappa \mathrm{B}$ pathway likely results in significant amplification of overall airway inflammation.

Additionally, TLR2-mediated intracellular signalling is markedly more resistant to the anti-inflammatory effects of corticosteroids than intracellular signalling mediated by TLR5 or TLR3 (a receptor for double-stranded RNA), as assessed by NF- $\kappa \mathrm{B}$ and p38 MAPK activation. p38 $\alpha$ MAPK is a protein kinase important for the transduction of $P$. aeruginosa-driven host responses [25] that can be dephosphorylated by DUSP1 in response to corticosteroids [26]. This difference cannot be explained by decreased activity of direct targets of corticosteroids, since both a GRE luciferase reporter and the endogenous induction of the well-known target gene DUSP1 were unaffected by the presence of either TLR2 or TLR5 ligands. These findings are particularly surprising since, based on current knowledge, both TLR2- and TLR5-activated signalling pathways are very similar [27]. They only differ by the requirement of the adaptor TIRAP to recruit the myeloid differentiation primary response protein MyD88 to the signalling complex of TLR2 heterodimers [28], but not TLR5 homodimers. Whether the presence of the TIRAP adaptor protein renders TLR2 signalling resistant to the anti-inflammatory action of corticosteroid remains to be investigated. The differential impact of corticosteroids on TLR2- versus TLR5-dependent signalling pathways may provide a possible explanation for the heterogeneous clinical efficacy of their use in the treatment of CF lung disease.

As the experimental studies were done in cell cultures, it is important to recognise that the effects of corticosteroids may differ in the lung tissue environment. For example, we have previously reported that in severe asthma, clinical corticosteroid resistance in patients is not well correlated with resistance in airway smooth muscle cells in culture [29], suggesting that tissue context plays a role in determining the overall response to corticosteroids.

A better understanding of how different bacterial phenotypes alter host interactions and the ensuing inflammatory response is critical to the optimal use of therapies such as corticosteroids $[17,18]$. Whether patients colonised with nonmucoid $P$. aeruginosa respond better to corticosteroids than patients colonised with mucoid $P$. aeruginosa remains to be examined in future clinical studies. If this proves to be true, other options for the treatment of corticosteroid-resistant inflammation should be investigated. For example, azithromycin and high-dose ibuprofen have both proven effective at decreasing inflammation in CF lung disease and to improve outcomes [30,31], and could be further explored.

\section{Acknowledgements}

Author contributions: M. Mizutani, J. Bérubé, H.G. Ahlgren, J. Bernier, E. Matouk, D. Nguyen and S. Rousseau made substantial contributions to the conception, design of the work and the acquisition, analysis or interpretation of data for the work. M. Mizutani, J. Bérubé, H.G. Ahlgren, J. Bernier, E. Matouk, D. Nguyen and S. Rousseau drafted the work and revised it critically for intellectual content. M. Mizutani, J. Bérubé, H.G. Ahlgren, J. Bernier, E. Matouk, D. Nguyen and S. Rousseau approved the final version to be published and agree to be accountable for all aspects of the work.

\section{References}

1 Sanders D, Bittner R, Rosenfeld M, et al. Failure to recover to baseline pulmonary function after cystic fibrosis pulmonary exacerbation. Am J Respir Crit Care Med 2010; 182: 627-632.

2 Cantin A, Hartl D, Konstan M, et al. Inflammation in cystic fibrosis lung disease: pathogenesis and therapy. $J$ Cyst Fibros 2015; 14: 419-430.

3 Golden BE, Clohessy PA, Russell G, et al. Calprotectin as a marker of inflammation in cystic fibrosis. Arch Dis Child 1996; 74: 136-139.

4 Doggett RG, Harrison GM, Carter RE. Mucoid Pseudomonas aeruginosa in patients with chronic illnesses. Lancet $1971 ; 1: 236-237$.

5 Adamo R, Sokol S, Soong G, et al. Pseudomonas aeruginosa flagella activate airway epithelial cells through asialoGM1 and toll-like receptor 2 as well as toll-like receptor 5. Am J Respir Cell Mol Biol 2004; 30: 627-634.

6 Blohmke C, Park J, Hirschfeld A, et al. TLR5 as an anti-inflammatory target and modifier gene in cystic fibrosis. $J$ Immunol 2010; 185: 7731-7738.

$7 \quad$ Zhang Z, Reenstra W, Weiner D, et al. The p38 mitogen-activated protein kinase signaling pathway is coupled to Toll-like receptor 5 to mediate gene regulation in response to Pseudomonas aeruginosa infection in human airway epithelial cells. Infect Immun 2007; 75: 5985-5992.

8 Greene C, Carroll T, Smith S, et al. TLR-induced inflammation in cystic fibrosis and non-cystic fibrosis airway epithelial cells. J Immunol 2005; 174: 1638-1646.

9 Lipuma J. The changing microbial epidemiology in cystic fibrosis. Clin Microbiol Rev 2010; 23: $299-323$.

10 Henry RL, Mellis CM, Petrovic L. Mucoid Pseudomonas aeruginosa is a marker of poor survival in cystic fibrosis Pediatr Pulmonol 1992; 12: 158-161. 
11 Konstan M, Wagener J, Vandevanter D, et al. Risk factors for rate of decline in $\mathrm{FEV}_{1}$ in adults with cystic fibrosis. J Cyst Fibros 2012; 11: 405-411.

12 Firoved A, Ornatowski W, Deretic V. Microarray analysis reveals induction of lipoprotein genes in mucoid Pseudomonas aeruginosa: implications for inflammation in cystic fibrosis. Infect Immun 2004; 72: 5012-5018.

13 Beaudoin T, Lafayette S, Nguyen D, et al. Mucoid Pseudomonas aeruginosa caused by mucA mutations result in activation of TLR2 in addition to TLR5 in airway epithelial cells. Biochem Biophys Res Commun 2012; 428: 150-154.

14 Eigen $\mathrm{H}$, Rosenstein BJ, FitzSimmons S, et al. A multicenter study of alternate-day prednisone therapy in patients with cystic fibrosis. Cystic Fibrosis Foundation Prednisone Trial Group. J Pediatr 1995; 126: 515-523.

15 Auerbach HS, Williams M, Kirkpatrick JA, et al. Alternate-day prednisone reduces morbidity and improves pulmonary function in cystic fibrosis. Lancet 1985; 2: 686-688.

16 Lai HC, FitzSimmons SC, Allen DB, et al. Risk of persistent growth impairment after alternate-day prednisone treatment in children with cystic fibrosis. N Engl J Med 2000; 342: 851-859.

17 Balfour-Lynn I, Welch K. Inhaled corticosteroids for cystic fibrosis. Cochrane Database Syst Rev 2016; 8: CD001915.

18 Cheng K, Ashby D, Smyth R. Oral steroids for long-term use in cystic fibrosis. Cochrane Database Syst Rev 2015; 12: CD000407.

19 Wojewodka G, De Sanctis JB, Bernier J, et al. Candidate markers associated with the probability of future pulmonary exacerbations in cystic fibrosis patients. PLoS One 2014; 9: e88567.

20 Bilton D, Canny G, Conway S, et al. Pulmonary exacerbation: towards a definition for use in clinical trials. Report from the EuroCareCF Working Group on outcome parameters in clinical trials. J Cyst Fibros 2011; 10: Suppl. 2, S79-S81.

21 Flume $\mathrm{P}$, Mogayzel J, Robinson $\mathrm{K}$, et al. Cystic fibrosis pulmonary guidelines: treatment of pulmonary exacerbations. Am J Respir Crit Care Med 2009; 180: 802-808.

22 Abbott J, Holt A, Hart A, et al. What defines a pulmonary exacerbation? The perceptions of adults with cystic fibrosis. J Cyst Fibros 2009; 8: 356-359.

23 Miller M, Hankinson J, Brusasco V, et al. Standardisation of spirometry. Eur Respir J 2005; 26: 319-338.

24 Bérubé J, Bourdon C, Yao Y, et al. Distinct intracellular signaling pathways control the synthesis of IL-8 and RANTES in TLR1/TLR2, TLR3 or NOD1 activated human airway epithelial cells. Cell Signal 2009; 21: 448-456.

25 Beaudoin T, LaFayette S, Roussel L, et al. The level of $\mathrm{p} 38 \alpha$ mitogen-activated protein kinase activation in airway epithelial cells determines the onset of innate immune responses to planktonic and biofilm Pseudomonas aeruginosa. J Infect Dis 2013; 207: 1544-1555.

26 Kassel O, Sancono A, Krätzschmar J, et al. Glucocorticoids inhibit MAP kinase via increased expression and decreased degradation of MKP-1. EMBO J 2001; 20: 7108-7116.

27 Rousseau S, Martel G. Gain-of-function mutations in the Toll-like receptor pathway: TPL2-mediated ERK1/ERK2 MAPK activation, a path to tumorigenesis in lymphoid neoplasms? Front Cell Dev Biol 2016; 4: 50.

28 Yamamoto M, Sato S, Hemmi H, et al. Essential role for TIRAP in activation of the signalling cascade shared by TLR2 and TLR4. Nature 2002; 420: 324-329.

29 Robins S, Roussel L, Schachter A, et al. Steroid-insensitive ERK1/2 activity drives CXCL8 synthesis and neutrophilia by airway smooth muscle. Am J Respir Cell Mol Biol 2011; 45: 984-990.

30 Ratjen F, Saiman L, Mayer-Hamblett N, et al. Effect of azithromycin on systemic markers of inflammation in patients with cystic fibrosis uninfected with Pseudomonas aeruginosa. Chest 2012; 142: 1259-1266.

31 Konstan MW, Byard PJ, Hoppel CL, et al. Effect of high-dose ibuprofen in patients with cystic fibrosis. $N$ Engl J Med 1995; 332: 848-854. 